\title{
Pulmonary Hypertension in the Critically III
}

\author{
Michelle S. Chew ${ }^{1}$, Anders Åneman², \\ John F. Fraser ${ }^{3}$ and Anthony S. McLean ${ }^{4}$ \\ ${ }^{1}$ Department of Intensive Care Medicine, \\ Skåne University Hospital Malmö, Lund University, \\ ${ }^{2}$ Intensive Care Unit, Liverpool Hospital, Sydney, \\ ${ }^{3}$ Critical Care Research Group, The Prince Charles Hospital, Brisbane, \\ 4Intensive Care Unit, Nepean Hospital, Sydney University, \\ ISweden \\ 2,3,4Australia
}

\section{Introduction}

Pulmonary hypertension (PHT) is frequently seen in the critically ill patient. PHT is defined as a mean pulmonary arterial pressure (MPAP) $>25 \mathrm{mmHG}$ at rest (Farber and Loscalzo, 2004; Task Force for the Diagnosis and Treatment of Pulmonary Hypertension of the European Society of Cardiology (ESC) and the European Respiratory Society (ERS), endorsed by the International Society of Heart and Lung Transplantation (ISHLT), 2009). The updated clinical classification (Dana Point 2008) describes pulmonary hypertension according to arterial or venous aetiology, as well as those associated with heart, respiratory and thromboembolic diseases (Table 1) (Task Force for the Diagnosis and Treatment of Pulmonary Hypertension of the European Society of Cardiology (ESC) and the European Respiratory Society (ERS), endorsed by the International Society of Heart and Lung Transplantation (ISHLT), 2009).

PHT is inextricably linked to respiratory and right ventricular (RV) function. Increased pulmonary vascular resistance increases the afterload of the right ventricle, eventually leading to RV dysfunction and failure. This is reflected clinically as systemic venous hypertension with the classical signs of distended neck veins, pulsatile hepatomegaly and peripheral oedema. A vicious cycle is set up as elevated right ventricular end-diastolic pressures worsens tricuspid insufficiency, which in turn aggravates splanchnic and peripheral venous engorgement, leading to organ failure by reducing the perfusion pressure within these organs (Figure 1). Due to ventricular interdependence, left sided filling and contractility also becomes impaired, further contributing to systemic hypotension and organ hypoperfusion. It is therefore not surprising that the presence of PHT and RV failure is associated with a poorer clinical outcome in ICU patients (Moloney et al., 2003; Osman et al., 2008; Ribiero et al., 1997; Viellard Baron et al., 2001).

ICU patients are at particular risk for developing PHT and RV failure for a number of reasons. Firstly, the presence of mechanical ventilation may impose an additional load on the RV. Secondly, ARDS inevitably increases pulmonary vascular resistance due to the presence of pulmonary vasoconstriction, which in turn may be triggered by hypoxia and the 
release of vasoconstrictive mediators. Thirdly, endothelial dysfunction and high risk for pulmonary vascular occlusion also contribute to increased pulmonary vascular resistance. It is estimated that approximately $25 \%$ of patients with ARDS have right ventricular dysfunction and pulmonary hypertension (Viellard Baron et al., 2001) .

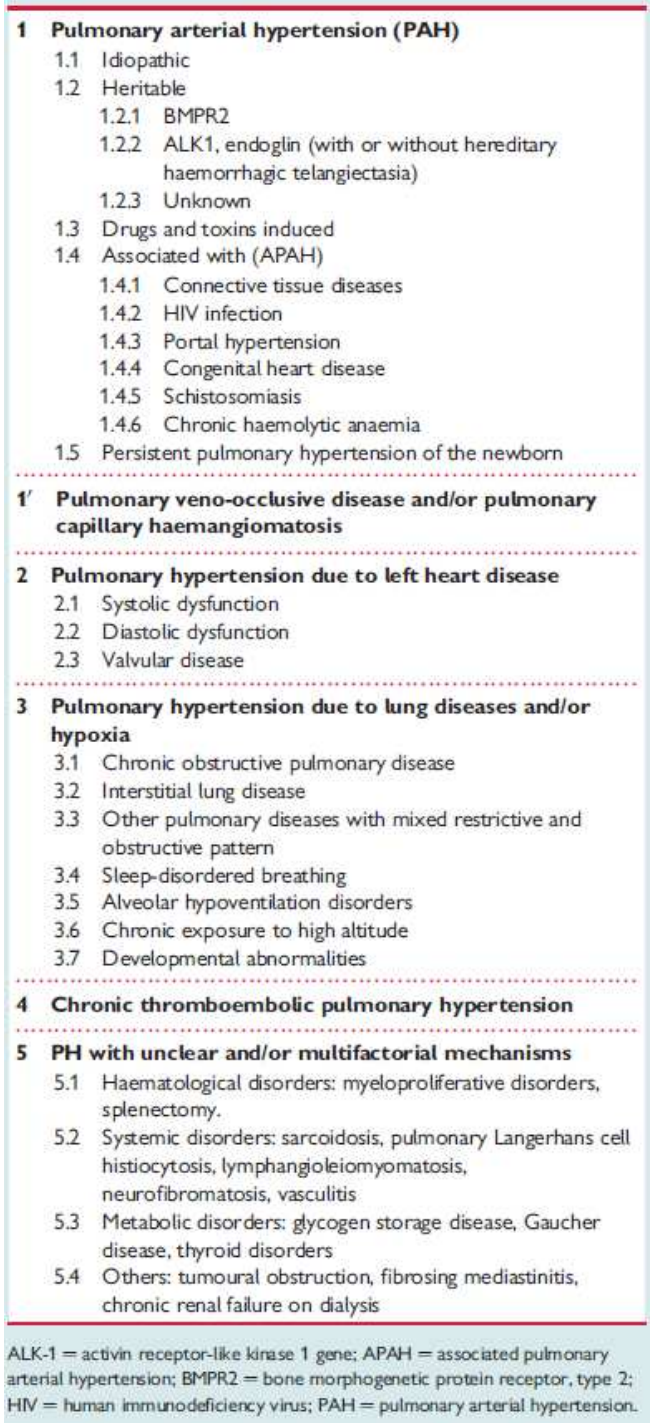

Table 1. Updated clinical classification of pulmonary hypertension (Dana Point 2008). Reprinted from the Task Force for the Diagnosis and Treatment of Pulmonary Hypertension of the European Society of Cardiology (ESC) and the European Respiratory Society (ERS), endorsed by the International Society of Heart and Lung Transplantation (ISHLT), 2009 with permission from Oxford University Press. 


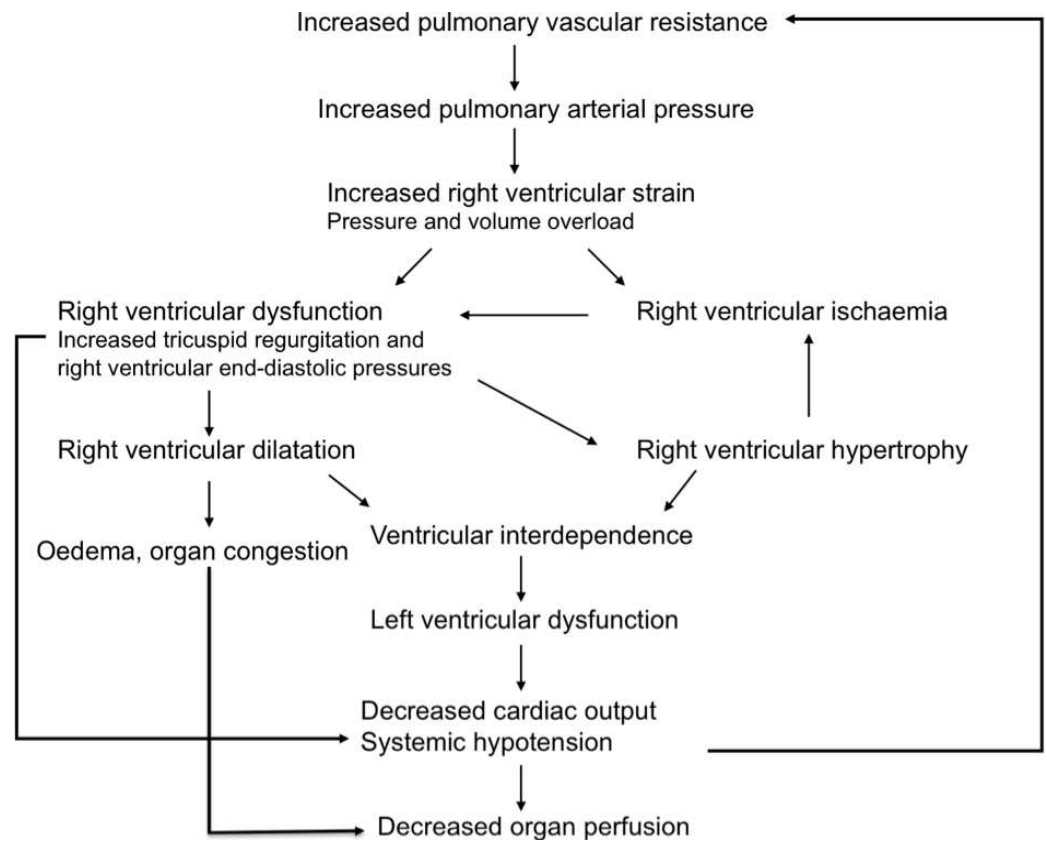

Fig. 1. Increased pulmonary vascular pressures lead to right ventricular dysfunction, impaired left sided filling and contractility, systemic hypotension and organ hypoperfusion.

Management of pulmonary hypertension in this group of patients is complex, given that the critically ill are often haemodynamically unstable, have varying responses to loading conditions on the heart, and are commonly mechanically ventilated. There is a complex interaction between the left and right ventricles, and management strategies that apply to non-ventilated inpatients or outpatients do not necessarily apply in the ICU setting.

In this paper we review the pathophysiology, diagnostic possibilities and discuss management strategies of PHT in the critically ill.

\section{Pathophysiology}

The molecular pathophysiology of pulmonary hypertension is complex and probably varies depending on causative factors. In general however, pulmonary hypertension may be regarded as an imbalance between vasodilatory and vasoconstrictive forces leading to abnormal vascular reactivity in the pulmonary vascular bed predisposing to vasoconstriction. Several molecular mechanisms have been implicated in the pathogenesis of pulmonary hypertension and the reader is referred to Farber \& Localzo, 2004 and Mandegar et al., 2004 for in-depth reviews. There are numerous experimental and clinical data demonstrating the importance of pulmonary vasocontrictors such as endothelin-1 (ET-1), serotonin, thromboxane and leukotrienes, acting against vasodilators such as adrenomedullin, nitric oxide (NO) and prostacyclin via second messengers such as cAMP and cGMP (Berkenbosch et al., 2000; Chew et al., 2008; Farber \& Localzo, 2004; Giaid et al., 1993; Giaid and Saleh, 1995; Moloney et al., 2003; Steudel et al., 1997; Zhao et al., 2003). Neurohormonal factors such as atrial and brain 
natriuretic peptides seem not only to be markers of disease severity, but play an active role by promoting cGMP mediated pulmonary vasodilation (Zhao et al., 2003). Hypoxic pulmonary vasoconstriction, a normally adaptive mechanism directing blood away from poorly ventilated areas may become maladaptive when sustained, contributing to increased pulmonary vascular resistance. At the cellular level, a number of mechanisms including potassium channel downregulation contribute to pathological intracellular calcium handling and homeostatis. The end result is smooth muscle proliferation, vascular remodelling and vasocontriction. Finally, genetic factors also play a role in the development of pulmonary hypertension. For example, an imbalance between apoptosis and proliferation is thought to occur as a result of mutations in bone morphogenetic receptor type II (BMP-R2) and polymorphisms in the serotonin receptor transporter (Mandegar et al., 2004; Newman et al., 2001) have been described.

\section{Diagnosis and haemodynamic monitoring of pulmonary hypertension}

\subsection{Monitoring}

The definition of to monitor is 'to watch over somebody or something, especially to ensure that good order or proper conduct is obtained'. The three components of monitoring are the subject matter, parameters measured, and periodicity chosen. Pulmonary hypertension being the subject matter leads to a number of parameters that should be considered for measurement including central venous pressure/right atrial pressure (CVP/RAP), pulmonary artery pressures (systolic, mean, diastolic), mixed venous oxygen saturation $\left(\mathrm{SvO}_{2}\right)$, cardiac output $(\mathrm{CO})$, right ventricular systolic function, and left ventricular end diastolic pressure or left atrial pressure (LAP). Periodicity will vary according to the clinical objectives, although in the critically ill patient parameters are likely to measured continuously, over hours or sometimes over days.

Two modalities are available to the physician managing the critically ill patient with PHT are (1) right heart catherization using the pulmonary artery catheter and (2) echoDoppler (ED) assessment.

\subsubsection{Pulmonary Artery Catheter}

Right heart catheterization using the pulmonary artery catheter (PAC) is the gold standard in the confirming the diagnosis and accurately monitoring the haemodynamic abnormalities on a minute-to-minute basis in PHT. PAH is defined by a MPAP $\geq 25 \mathrm{~mm} \mathrm{Hg}$ at rest and by a pulmonary vascular resistance (PVR) $>3 \mathrm{~mm} \mathrm{Hg} / 1$ (Wood units) (Task Force for the Diagnosis and Treatment of Pulmonary Hypertension of the European Society of Cardiology (ESC) and the European Respiratory Society (ERS), endorsed by the International Society of Heart and Lung Transplantation (ISHLT), 2009), with further subclassification into precapillary or postcapillary PHT determined by the pulmonary capillary wedge pressure (PCWP) and transpulmonary gradient $(\mathrm{TPG}=\mathrm{MPAP}-\mathrm{PCWP})$. In addition to the benefit of RHC in obtaining an accurate PAP measurement, it should be utilized where rapid assessment of responses to intravenous or nebulised therapy is required. Although the emphasis may be on the PAP, including the systolic (SPAP), mean (MPAP) and diastolic (DPAP) pulmonary arterial pressures, other parameters including cardiac output, pulmonary vascular resistance, mixed venous oxygen saturation and the PCWP may contribute to the evaluation. These should be measured in conjunction with systemic circulation parameters including arterial oxygen saturation and blood pressure. 


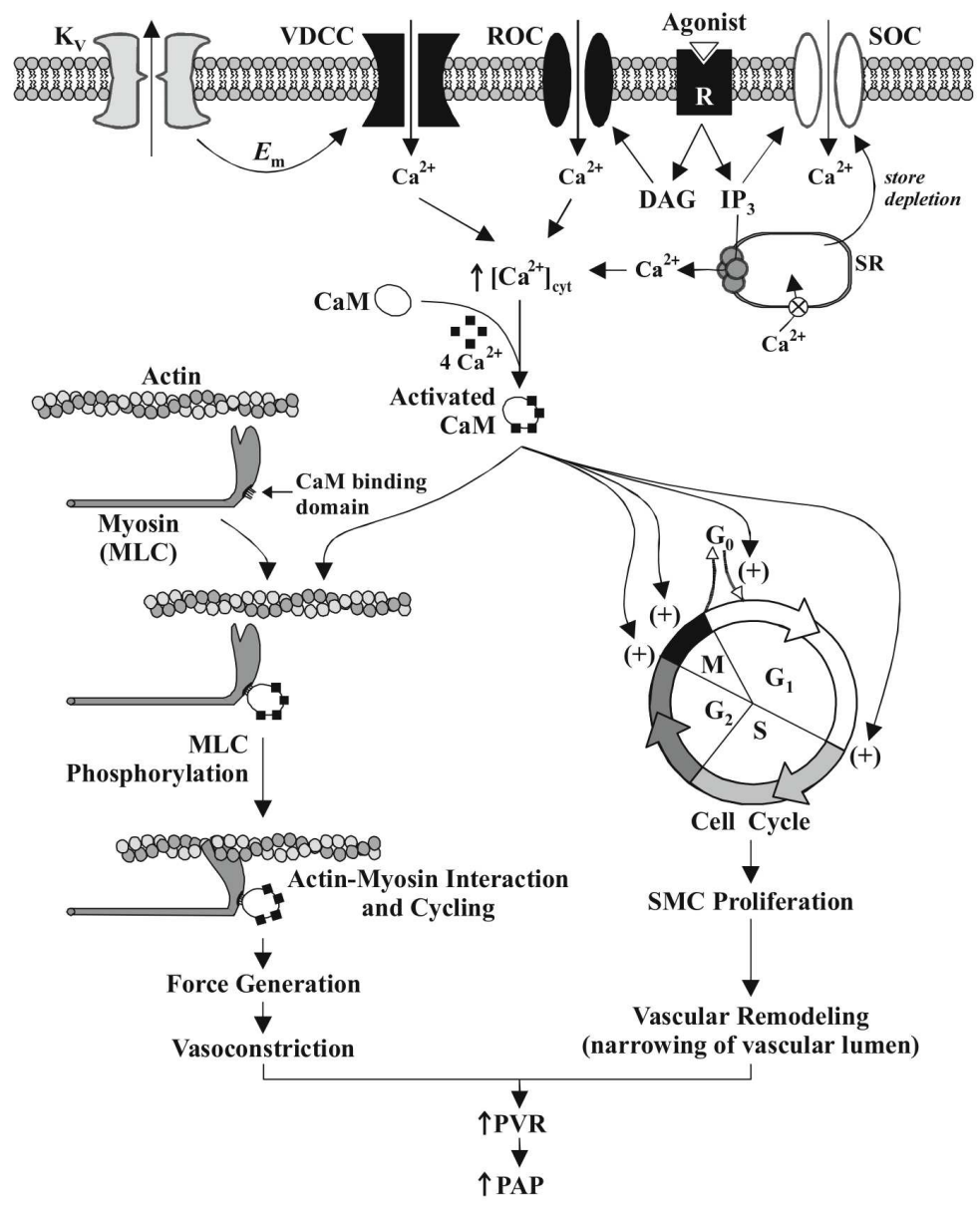

Fig. 2. Increased intracellular calcium $\left[\mathrm{Ca}^{2+}\right]_{\text {cyt }}$ triggers pulmonary vasoconstriction and promotes pulmonary vascular remodeling via several mechanisms: 1 . Decreased activity of voltage-gated $\mathrm{K}^{+}$channel $(\mathrm{Kv})$ leading to opening of voltage dependent $\mathrm{Ca}^{2+}$ channels (VDCC), 2. Activation of receptors (R), such as G-protein coupled receptors leading to the production of second messengers such as diacylglycerol (DAG) and inositol 1,4,5 triphosphate (IP3), which mobilizes intracellular $\mathrm{Ca}^{2+}, 3$. Activation of receptor operated $\mathrm{Ca}^{2+}$ channels (ROC), 4. Opening of store-operated $\mathrm{Ca}^{2+}$ channels (SOC) by store depletion inducing $\mathrm{Ca}^{2+}$ mobilization from the sarcoplasmic reticulum (SR). $\mathrm{Ca}^{2+}$ binds to Calmomodulin (CaM), and the $\mathrm{Ca}^{2+} / \mathrm{CaM}$ complex activates myosin light chain kinase, phosphorylating the myosin light chain (MLC). This leads to crossbridge formation with actin filaments. The $\mathrm{Ca}^{2+} / \mathrm{CaM}$ complex also activates steps in the cell cycle propelling quiescent cells into mitosis (M) and cellular proliferation (+). The end result is vasoconstriction, smooth muscle proliferation and vascular remodelling leading to sustained elevations in pulmonary vascular resistance. Reprinted from Mandegar et al. (2004) with permission from Elsevier. 
Testing acute vasodilator responses using short-acting agents such as intravenous adenosine and prostacyclin, or inhaled nitric oxide, should be undertaken in a systematic and careful manner. A positive vasoreactive response is defined as a reduction of MPAP mean PAP $\geq 10$ $\mathrm{mmHg}$ to reach a MPAP mean PAP $\leq 40 \mathrm{~mm} \mathrm{Hg}$ with an increased or unchanged CO (Galie et al., 1995). While the RHC has clear advantages over ED for precise PAP, $\mathrm{SvO}_{2}$ and minuteto-minute monitoring, it carries the disadvantage of being invasive and having limited ability to assess other relevant parameters such as RV function and size, left heart function and the presence of confounding pathologies like intercardiac shunts and significant valvular dysfunction.

\subsubsection{Doppler echocardiography}

Doppler echocardiographic monitoring of PAP began over 30 years ago when Hatle and colleagues applied Doppler ultrasound to calculate the time difference between PV closure and TV opening to estimate SPAP, basing the approach on earlier work by Burstin (Burstin, 1967; Hatle et al., 1981).

Not only is PAP obtainable noninvasively in the great majority of patients, but important associated right and left heart evaluations can be made and repeated when desired. An example would be where the PHT is secondary to pulmonary embolic disease and assessment of right heart structure and function to evaluate chronicity can be undertaken. The presence of significant RV wall hypertrophy indicates longstanding pathology; alternatively in the setting of acute PE the SPAP is unlikely to rise beyond $40 \mathrm{~mm} \mathrm{Hg}$ (McIntyre \& Sasahara, 1971; Fisher et al., 2009). Guidelines recommend the subcostal (SC) 4chamber view for measurements of RV wall thickness, which correlates with RV systolic pressure (Lang et al., 2005).

Parameters measured directly or indirectly in PHT by ED include CVP/RAP, SPAP, DPAP, MPAP, RV systolic function, CO, and LAP.

\subsubsection{Right atrial pressure}

The calculation of this specific parameter using echocardiography has been established in haemodynamically stable, supine, spontaneously ventilated patients for many years using IVC diameter (D) changes, determined from the SC view, throughout the respiratory cycle (Brennan et al., 2007). A large IVC diameter $(>21 \mathrm{~mm})$ with $<35 \%$ collapsibility index ( $D_{\text {expiration }}-\mathrm{D}_{\text {inspiration}} / \mathrm{D}$ inspiration $\mathrm{X} 100 \%$ ) gives an RAP of $10-20 \mathrm{mmHg}, 35-50 \%$ an RAP $10-15$ $\mathrm{mm} \mathrm{Hg},>55 \%$ an RAP $0-10 \mathrm{~mm} \mathrm{Hg}$. A smaller IVC ( $<21 \mathrm{~mm})$ with a collapsibility index of $35-55 \%$ gives a RAP 0-10 $\mathrm{mm} \mathrm{Hg},>55 \% 0-5 \mathrm{~mm} \mathrm{Hg}$. Unfortunately the relationship doesn't hold for critically ill positive pressure ventilated patients when attempting to obtain a static RAP measurement. It does have value in determining fluid responsiveness in patients on controlled ventilation using the Distensibility Index or IVC variability index, but for the purposes of calculating a PAP a static measurement is required (Barbier et al., 2004; Feissel et al., 2004). Since many of these patients will have a central line in-situ it is recommended that the invasively obtained CVP be added to the ED derived RV-RA gradients.

\subsubsection{Pulmonary artery pressures}

(i) Systolic pulmonary artery pressure (SPAP)

The tricuspid regurgitant (TR) jet method is the most commonly used method in clinical practice. It is operator dependent and this factor alone could explain the modest sensitivity 
and specificity identified in a recent metanalysis (Janda et al., 2011). The preferred approach is to apply the continuous wave spectral Doppler across the tricuspid valve from either the apical 4 chamber (A4C) and/or parasternal short axis (PSAX) view, with careful attention to the angle of insonation to obtain the maximal regurgitant velocity. The modified Bernoulli equation is applied to calculate the RV-RA gradient, with subsequent addition of the RAP to calculate the SPAP. If an adequate TR jet is obtained the correlation with RHC-obtained SPAP measurements is very good (Janda et al., 2011). An experienced operator will take time to optimize the Doppler signal, especially when confounding factors such as minimal TR is present, the jet is eccentric, or there is poor coaptation of the tricuspid valve leaflets resulting in a broad turbulent jet.

\section{Diagnosis in the absence of tricuspid regurgitation: Nepean Index}

Using a combination of tissue Doppler velocity (TDI) of the lateral tricuspid annulus and the $\mathrm{RV}$ enddiastolic diameter (RVD), the ratio of $\mathrm{RVD} / \mathrm{T}_{\text {peak }}$ (where $\mathrm{T}_{\text {peak }}=$ duration of TDI from the start of isovolumic contraction to peak systole) of $>22 \mathrm{~cm} / \mathrm{sec}$, predicted the presence of PHT, diagnosed as SPAP > $35 \mathrm{~mm} \mathrm{Hg}$, with $80 \%$ sensitivity and $83 \%$ specificity in patients with or without RV dysfunction (McLean et al., 2007).

\section{(ii) Mean pressure}

The diagnosis of pulmonary hypertension is based on the MPAP as measured by highfidelity RHC measurements where the MPAP is measured as the area under the pressure curve divided by the pulse interval (Badesch et al., 2009; McGoon et al., 2004).

In clinical practice a flotation pulmonary artery catheter is generally utilized, which estimates the MPAP by the formula MPAP=2/3DPAP+1/3SPAP. An extension therefore is to calculate the MPAP in a similar fashion utilizing ED derived SPAP and DPAP. Interestingly, further analysis indicates that SPAP is responsible for $98 \%$ of MPAP variability and therefore the use of the single parameter SPAP should be sufficient to accurately measure MPAP (Chemla et al., 2009). In investigating 2 separate formulae, the Chemla and Syyed formulae, where only the SPAP and not the DPAP is used, Aduen and colleagues demonstrated similar accuracy and precision to RHC-obtained measurements by ED derived measurements, indicating they were suitable for clinical use (Aduen et al., 2011) 30. $^{30}$

Chemla formula: MPAP $=0.61 \times \mathrm{SPAP}+2 \mathrm{~mm} \mathrm{Hg}$ Syyed formula: $\mathrm{MPAP}=0.65 \times \mathrm{SPAP}+0.55 \mathrm{~mm} \mathrm{Hg}$

It has also been shown that the relationship between SPAP and MPAP remains linear during activity and change in posture (Syyed et al., 2008).

(iii) Pulmonary artery diastolic pressure

DPAP can be estimated using the pulmonary regurgitant jet. The velocity at end diastole is calculated and the modified Bernoulli equation is used.

eg. $\quad \mathrm{DPAP}=4 \times \quad$ (pulmonary regurgitant end diastolic velocity $)^{2}+\mathrm{RAP}$

\subsubsection{Cardiac output}

This parameter can be obtained using the Simpsons Method from analysis of the left ventricular dimensions in the $\mathrm{A} 4 \mathrm{C}$ and $\mathrm{A} 2 \mathrm{C}$ views. Measurement of both left ventricular end diastolic and end systolic volumes is undertaken. The ultrasound machine has inbuilt 
software that utilizes division into multiple discs and a resultant summation in the overall volume leading to a simple method of calculating $\mathrm{CO}$. This along with the left ventricular outflow tract (LVOT) Doppler method of calculating the cardiac output has been validated in the critically ill population (McLean et al., 1997).

The latter method is more reliable but does require more experience because continuous wave $(\mathrm{CW})$ Doppler is involved. The more experienced operator should adopt the latter approach. The right ventricular outflow can also used in preference to the LVOT if desired.

\subsubsection{RV systolic function}

Assessment of right ventricular contraction on a regular basis in a critically ill patient with PHT is absolutely essential. Prognosis depends on the ability of the RV to adapt to elevated PAP, and being a thinned wall chamber its ability to adapt to systolic demands is limited. RV contractility can be monitored subjectively or objectively.

The subjective assessment of RV contraction relies upon both chamber sizes and visual 'eyeballing ' of the RV free wall. Dilatation of the RV is a guide to pulmonary pressure and/or fluid status. The relative area or volume of the RV to the LV as seen in the A4C view using transthoracic echocardiography or mid-oesphageal view using transoesophageal echocardiography should be $<0.6$, with a ratio of $>1.0$ indicating marked RV dilatation and 0.6-1.0 moderate dilatation. Paradoxical septal motion, usually best seen in the parasternal short axis view, adds to the evaluation with abnormal systolic motion indicating pressure overload and abnormal diastolic motion indicating RV fluid overload. The free wall of the RV is best viewed in the SC and A4C views although may be visualized in other views. Particular attention to RV wall thickness should be taken to assist in determining the chronicity of the PHT.

A number of parameters have been used in the evaluation of RV systolic function but most studies have demonstrated the clinical value of Right ventricular Myocardial performance index (RV MPI), tricuspid annulus plane systolic excursion (TAPSE), fractional area change (FAC) and $S^{\prime}$ of the tricuspid annulus (Rudski et al., 2010).

\section{i) Right Ventricular Myocardial Performance Index}

The Myocardial Performance Index or 'Tei Index' was initially validated as a index of global left ve ntricular function but became adapted to the right heart (Karnati et al., 2008). RV MPI requires PW or CW Doppler recordings of the TV inflow and RV outflow. RV MPI is calculated from the isovolumic contraction time, isovolumic relaxation time and ejection time. A RV MPI $>0.40$ indicates global RV dysfunction. If tissue Doppler of the lateral tricuspid annulus is used, then global RV dysfunction is present if the RV MPI $>0.55$. The latter avoids errors related to variability in heart rate although both are less accurate with increasing RA pressures because of a decrease in the IVRT.

ii) TAPSE

The tricuspid annulus plane systolic excursion (TAPSE), otherwise known as the Tricuspid Annulus Displacement (TAD), is a parameter obtained by placing the M-mode cursor over the lateral tricuspid annulus. Although only one small part of RV motion is evaluated, this single simple measurement has been demonstrated to be a relatively reliable guide in both diagnostic and prognostic studies. A TAPSE of $16 \mathrm{~mm}$ or less implies RV contractile impairment (Forfia et al., 2006; Rudski et al., 2010). 


\section{iii) Right Ventricular Fractional Area Change}

RV FAC is defined as (enddiastolic area -endsystolic area)/enddiastolic area x 100 and correlates with MRI evaluation of RV systolic function (Anavekar et al., 2007). Measurements of FAC are taken in the A4C view with the RV cavity area traced from the tricuspid annulus along the free wall and back down the ventricular septum, in both systole and diastole. A normal RV FAC is $>35 \%$.

\section{iv) S' obtained by Tissue Doppler Imaging}

From the $\mathrm{A} 4 \mathrm{C}$ view the tricuspid annulus and basal free wall segments of the right ventricle can be assessed by either pulsed tissue Doppler or colour tissue Doppler to measure longitudinal velocity excursion. The $S^{\prime}$ velocity of the basal free wall measured by pulsed wave Doppler is the recommended value to measure (Rudski et al., 2010). Population studies give normal values of $15 \mathrm{~cm} / \mathrm{sec}$ at the annulus and basal free wall. The lower limit of normal can be taken as $10 \mathrm{~cm} / \mathrm{sec}$ (Lindqvist et al., 2005).

This is a simple and reproducible parameter with a $S^{\prime}<10 \mathrm{~cm} / \mathrm{s}$ indicating abnormal $\mathrm{RV}$ systolic function in adult patients.

\subsubsection{Left atrial pressure}

Either direct measurement of the LAP, or a surrogate, is essential when monitoring PHT. The contribution of left heart dysfunction, or lack thereof, needs to be established. Also, over time an elevated PAP needs to be continually assessed, particularly in a patient with underlying PHT who is failing to improve and where LV dysfunction or elevated LAP develops during the ICU stay. A subjective view of the left heart may identify contractile dysfunction or significant left ventricular wall hypertrophy suggesting the presence of clinically relevant diastolic dysfunction. A number of methods including analysis of the mitral inflow wave form, pulmonary venous waveform, and M-Mode colour Doppler across the mitral inflow have been used historically for diastolic assessment, as a guide to elevated LAP. However, today the application of TDI makes the situation easier, particularly when combined with a dilated left atrium. The $\mathrm{E} / \mathrm{E}^{\prime}$ is of proven value in identifying elevated left atrial pressure, particularly when combined with a dilated left atrium.

\subsection{Periodicity of measurements}

The third component of the monitoring triad is that of periodicity and this may dictate which technique should be chosen in a particular patient. If daily assessment of the selected parameters is sought then ED in the majority of patients is sufficient. Where minute-to-minute monitoring is required and the parameters are limited to PAP and CO then the RHC should be considered. Where parameters are to be measured every few hours than the choice may depend on the availability and expertise present in the ICU. A word of caution is that if the RHC is chosen, then an ED should also be undertaken at some stage allowing for a better overall assessment of cardiovascular status. Conversely if very precise PAP measurements are required then a RHC should be chosen. Table 2 summarizes the main characteristics, advantages and disadvantages of the two modes of monitoring. 


\begin{tabular}{|c|c|c|}
\hline & $\begin{array}{c}\text { Pulmonary Artery } \\
\text { Catheter }\end{array}$ & Echo Doppler \\
\hline Ease of use & Requires training & Requires training \\
\hline Portability & No & Yes \\
\hline $\begin{array}{c}\text { User } \\
\text { dependence }\end{array}$ & $\begin{array}{c}\text { No, but data interpretation } \\
\text { requires training }\end{array}$ & $\begin{array}{c}\text { Yes, for data acquisition and } \\
\text { interpretation }\end{array}$ \\
\hline $\begin{array}{c}\text { Continuous } \\
\text { measurement }\end{array}$ & Yes & No \\
\hline Invasive \\
$\begin{array}{c}\text { CO } \\
\text { measurement }\end{array}$ & Yes & Yes \\
\hline $\begin{array}{c}\text { Pressure } \\
\text { measurements }\end{array}$ & Yes & Indirect, pressure are calculated \\
\hline $\begin{array}{c}\text { Evaluation of } \\
\text { RV function }\end{array}$ & No & Yes \\
\hline
\end{tabular}

Table 2. Characteristics of PAC and ED monitoring

\section{Heart-lung interactions and mechanical ventilation}

Mechanical interactions between the respiratory and circulatory systems are produced by changes in the intrathoracic pressure (ITP) and changes in the lung volume. The institution of positive pressure ventilation (PPV) profoundly affects both ITP and lung volumes. To add further complexity, these effects may vary considerably between the healthy state and during disease, particularly in acute respiratory failure (ALI/ARDS). Pulmonary hypertension (PHT) is a notable feature of ALI/ARDS.

The heart and lungs are anatomically linked by their shared position in the thorax, with the vascular compartments acting like pressure chambers within a pressure chamber during PPV. This has important implications for the heart-lung interactions. The serial vascular arrangement of the heart and lungs means that any changes of right ventricular (RV) function will change pulmonary perfusion that in turn will change left ventricular (LV) function (Figure 3).

The venous return determines RV and LV output that must remain equal albeit small variations occur from heartbeat to heartbeat. Furthermore, the right and left ventricles of the heart are linked to each other by common myocardial tissue, the septal wall and the enclosure in the fibrous, non-compliant pericardial sac. These features result in ventricular interdependence, i.e. forces are transmitted from one ventricle to the other (Bove \& Santamore, 1981). Diastolic ventricular interdependence means that increased volumepressure in one ventricle will shift the compliance curve of the other ventricle to the left and upward (Weber et al., 1981). Diastolic interdependence is present during physiological conditions and is accentuated by PPV. Conditions involving the pericardium, e.g. cardiac tamponade and constrictive pericarditis, further accentuate diastolic ventricular interdependence. Systolic ventricular interdependence occurs as a physiological phenomenon and experimental data suggest that $20-40 \%$ of right ventricular systolic pressure result from left ventricular contraction (Damiano et al., 1991). The greater part of ventricular interdependence occurs through the septum although the ventricular free wall is 
also involved. Conditions that decrease the relative compliance of the septum, such as volume overload, increase ventricular interdependence as does increased stiffening of the right ventricle, for example by PHT (Santamore \& Dell'Italia, 1998).

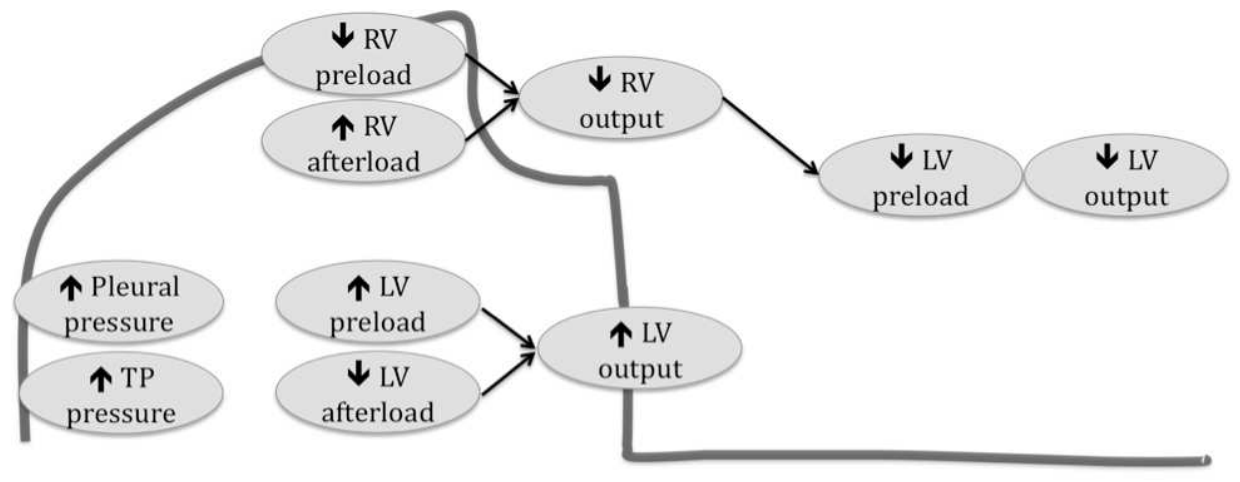

Inspiration

Expiration

Fig. 3. Heart-lung interactions - effects of mechanical ventilation. Increased transpulmonary pressure due to positive pressure ventilation increases RV afterload, whilst RV preload is decreased due to the decreased venous return. During the inspiratory phase, LV preload is transiently increased due to a 'squeezing' effect from pulmonary vasculature into the left atrium. Ultimately however, the decrease in RV filling leads to decreased LV filling and output. $\mathrm{TP}=$ transpulmonary pressure=alveolar-pleural pressure. Adapted from Michard \& Teboul (2000).

The RV preload is determined by the venous return, governed by the pressure gradient between mean systemic pressure and right atrial pressure, as well as caval size and collapsibility. Increased ITP generated by PPV may thus reduce venous return by decreasing the mean systemic to right atrial pressure gradient and by compressing the cavae, limiting flow (Michard \& Teboul, 2000; Shekerdemian \& Bohn, 1999). These effects can be offset by intravascular volume loading to increase mean systemic pressure, by increasing the extrathoracic pressure on large vessels, e.g. increasing intraabdominal pressure to increase mean systemic pressure, or by increasing venous vascular tone (through sympathetic activation or drugs). The classical effects of PEEP originally described by the two Nobel laureates Cournand and Richards (Cournand et al., 1948) are clinically not as prominent probably related to increased intraabdominal pressure by the diaphragmatic descent produced by PEEP and by sympathetic activation. Normally RV diastolic compliance is so high that RAP changes largely reflects changes in pericardial pressure rather than RV filling per se. Hence RAP is a poor indicator of RV end-diastolic filling. In patients with decreased RV compliance, such as in PHT, the dissociation between RAP and RV end-diastolic filling is lost.

LV function is influenced by PPV via the effects on RV function, thus governing LV filling, and by reduction of thoracic aortic transmural pressure leading to increased compliance and hence reduced LV afterload. Reduction of LV transmural pressure, and as a result LV mural 
tension, decreases oxygen consumption and forms the rationale for using PPV in patients with acute heart failure (Räsänen et al., 1985).

The ITP and airway pressures influence vascular pressures, but the extent and regional distribution of this effect may differ considerably in ALI/ARDS due to the uneven distribution of lung volume and alveolar pressure. Poorly compliant lungs, characteristic of ALI/ARDS, generally "protect" the vasculature from high airway pressures, meaning that PHT in this setting might not be as closely related to airway pressures as seen in less diseased lungs (Jardin et al., 1985). More precisely, the ITP significantly influences transmural pressure, i.e. the intravascular to ITP difference. This needs to be considered when assessing cardiac filling pressures as well as pulmonary vascular resistance (PVR). Increased ITP during PPV will decrease RV and LV filling in the setting of unchanged chamber pressures, since the transmural pressure decreases, even if RV and LV functional characteristics remain unchanged. The PVR is a complex variable, consisting of Poiseulle and Starling resistors, the details of which are beyond the context of the present review, and should not be viewed in the simplistic "Ohmic" manner typically applied to the systemic circulation (Versprille, 1984). The pulmonary blood is the sum of RV output and shunt flow from bronchial arteries to the pulmonary artery. The latter might increase significantly in RV failure and PHT to maintain pulmonary perfusion. Pulmonary vascular resistance is equally divided between pulmonary arteries/arterioles, capillaries and venules/veins. Active neurogenic and humoral vasoconstriction plays a minor role to control resistance and as a consequence regional distribution of pulmonary flow depends on other factors including gravity and hypoxic pulmonary vasoconstriction.

Oesophageal pressure can be used to estimate the ITP, and thus to work out vascular transmural pressures. Similarly, the transpulmonary pressure can be assessed, determining the stretch of the lungs. The caveat of airway pressure not being uniformly transmitted onto intrathoracic structures, including the oesphagus, must be kept in mind (Jardin et al., 1985).

Mechanical ventilation has complex effects on (PVR). In respiratory failure PPV can reduce PVR by increasing oxygenation above above $60 \mathrm{~mm} \mathrm{Hg}$ to alleviate hypoxic pulmonary vasoconstriction (HPV). Furthermore, sympathetic outflow can be diminished by reducing work of breathing and by increasing alveolar ventilation to attenuate respiratory acidosis. The relationship between lung volume and PVR is U-shaped with increased PVR occuring at low lung volumes (due to increased resistance in extra-alveolar vessels and alveolar collapse increasing HPV) and at high lung volumes (due to hyperinflation and increased alveolar pressure compressing alveolar vessels) (Whittenberger et al., 1960). PVR is lowest at FRC that is typically reduced in ALI. The effects of PEEP on PVR are highly dependent on the intravascular volume status. Increased intravascular filling mitigates the potential of raised ITP to transfer lung areas from West zone 3 to zones 1 or 2 (Fourgéres et al., 2010).

Ventilator settings for patients with PHT with incipient or manifest RV failure should be tailored to minimize inspiratory swings in ITP, i.e. small tidal volumes $(6 \mathrm{ml} / \mathrm{kg})$ delivered with a slow rise to peak inspiratory pressure. The expiratory drop in ITP should be rapid with the expiratory time set to minimize intrinsic PEEP, usually meaning expiratory time should at least equal the inspiratory time.

Severely increased PVR either acutely or added onto pre-existing PHT, for example by mechanical ventilation, can precipitate acute cor pulmonale with RV distension, septal 
flattening and leftward displacement with impaired LV filling and rapid haemodynamic deterioration. Fluid administration in this setting can further worsen RV failure and the use of extracorporeal circulation might be the only therapeutic option for the acutely pressureand volume-overloaded RV (Höhn et al., 1999).

\section{Current therapeutic strategies}

Pharmacological management of right heart failure and pulmonary vascular disease in the intensive care is dependent on its aetiology. While pulmonary hypertension may be due to left heart and/or underlying lung disease, its ultimate effects on the right heart are considered to be particularly deleterious. There are many components that can be related to the clinical syndrome of right heart failure seen in the critical care patient. This includes hypoxic pulmonary vasoconstriction, microvascular thromboses, increase or decrease of the permeability of the pulmonary vasculature and endothelial dysfunction. Further, changes in the lungs may precipitate right ventricular failure. RV failure may be primarily be related to RV function - for example due to ischemia of the right ventricle, volume overload or sepsis - or be secondary to LV failure. The management protocol of right ventricular dysfunction is dependent on the aetiology of the disease process, and these must be addressed prior to the isolated management of RV dysfunction. We will concentrate on specific management of RV dysfunction from this point onwards.

Management of RV dysfunction can be separated into surgical and pharmacological.

\subsection{Surgical management}

\subsubsection{Intra Aortic Balloon Pump (IABP)}

IABPs can support LV dysfunction but is of limited use in RV dysfunction. This is due to the differences in timing of coronary arterial filling of left and right coronary arteries. As the IABP inflates during diastole, it substantially augments left coronary filling. However the right coronary artery fills throughout systole and diastole, hence any diastolic augmentation of coronary filling is relatively small in the RV. Equally, IABP decreases the afterload for the left ventricle, but this does not affect right ventricular afterload. Right coronary perfusion is affected by the gradient between the intra ventricular pressure in the right ventricle and the coronary perfusion pressure - so the RV pressure must also be optimized, as too high an RV pressure will induce RV ischaemia. Pulmonary arterial pressures are raised by positive pressure ventilation hence all efforts should be made to move as rapidly as possible to negative pressure ventilation. Many centers will tracheostomise patients for this process. Equally if there is a risk of hypoxic pulmonary vasoconstriction, optimisation and maintaining a PO2 $>100 \mathrm{mHg}$ may reduce any pulmonary arterial vasoconstriction and hence decrease RV afterload.

\subsubsection{Assist devices}

Mechanical assist devices have been developed specifically with left ventricular support in mind. First generation ventricular assist devices such as Thoratec PVAD ${ }^{\mathrm{TM}}$ (Pleasanton, California, USA) and Abiomed BV5000'TM (Massachusetts, USA) can be used in the biventricular setting. However this limits mobilization of the patient. A short-term device such as Levotronix ${ }^{\mathrm{TM}}$ (Massachusetts, USA), or extracorporeal membrane oxygenation 
(ECMO) can improve RV dysfunction in the acute setting but again limits the mobility of the patient and the ability to move from intensive care. In the setting of long term mechanical $\mathrm{RV}$ support, work is ongoing regarding the development of an implantable biventricular devices/total artificial heart, and using two rotary pumps in series, (Timms et al., 2008) one for left and one for right ventricular support (Gregory et al., 2011). This necessitates either changing pump speeds or crimping the outflow of the VAD placed in the right heart to decrease pressures consistent with pulmonary arterial pressure (Timms et al., 2011). This would only be used in the chronic setting which is refractory to medical management. Whilst laboratory research has not been completed, some centres have already used this technique clinically (Strueber et al., 2010).

\subsection{Pharmacological management}

The pharmacological management of right ventricular dysfunction should aim at:

1. Prevention of right ventricular ischemia;

2. Improving right ventricular cardiac output;

3. Reducing pulmonary vascular resistance to a greater degree than systemic vascular resistance.

\subsubsection{Prevention of right ventricular ischemia}

Right ventricular ischaemia is clearly associated with increased mortality (Jacobs AK et al., 2003). Since the right coronary artery is filled through both systole and diastole with the majority of flow occurring through systole, the aortic root pressure is a key determinant of right coronary filling. Adequate systolic pressure is therefore required to optimize right ventricular oxygenation and this may necessitate vasopressor support. Vasopressors should be used carefully since they may increase left ventricular afterload, resulting in a shift of the intraventricular septum towards the right ventricle and reducing its output (see Section 4). Vasopressors which increase systemic systolic pressure may also increase pulmonary vascular pressure and the resistance which the failing right ventricle has to oppose. Therefore there is a trade-off between increasing right coronary perfusion pressures and increasing left and right ventricular afterload. Phenylephrine is well recognised to worsen right ventricular function. The data for Adrenaline and Noradrenaline are less clear. Increased, unchanged or decreased pulmonary vascular resistance (PVR) have been documented (Ghighone et al., 1984; Hirsch et al., 1991; Le Tulzo et al., 1997)

Vasopressin has some attributes suggesting it may be useful in patients with pulmonary vascular disease and RV dysfunction. In conscious animal models, vasopressin induces reversed drug induced vasoconstriction and induced pulmonary vasodilation (Trempy et al., 1994). In an ex-vivo model Evora et al describe how Vasopressin induces pulmonary vasodilatation due to a release of nitric oxide whilst simultaneously inducing systemic vasoconstriction. (Evora et al., 1993). The data in humans is much less clear. When Vasopressin and Noradrenalin were used to mitigate the hypotension associated with Milrinone Jeon et al noted that Vasopressin induced differential effects in the systemic and pulmonary vasculature, with a beneficial reduction in the PVR/SVR ratio following vasopressin only (Jeon et al., 2006). As has been described, maintenance of systemic pressure to optimize right coronary filling, with minimal or no simultaneous increase in PVR are ideal attributes in patients with the failing right ventricle. 
Hence, data is clear that Phenylephrine seems to be deleterious in the face of right ventricular dysfunction; Noradrenalin improves coronary filling and may improve cardiac output, while animal and limited human data suggest that Vasopressin increases systemic pressure with minimal adverse effects on the pulmonary circulation.

\subsubsection{Improving right ventricular cardiac output}

Vasopressors may improve cardiac output through increasing coronary filling. However, there is more data to support the use of inotropic agents such as Levosimendan, Dobutamine, Milrinone and Adrenaline in right ventricular failure although Noradrenaline should not be entirely dismissed. Inodilators such as Dobutamine have a number of properties that make it ideal in the face of pressure overload of the RV. In causing systemic vasodilation it reduces the preload to the right ventricle and improves right ventricular contractility with minimal effect on pulmonary vascular resistance. (Pagnamenta et al., 2003). Some data support the use of Levosimendan in the similar situation, where it increases in cardiac output by increasing right ventricular contractility, decreasing pulmonary vascular resistance and improving RV-PA coupling (Kerbaul et al., 2006). Of note, there are few studies of Levosimendan for the treatment of sepsis-induced cardiomyopathy and pulmonary hypertension.

The phosphodiesterase-3 (PDE3) inhibitors improve cardiac output through improved contractility and reduction in both systemic and pulmonary arterial pressure. Milrinone is the most commonly used drug of this family at present. However in patients with severe right ventricular dysfunction an associated renal failure, drug accumulation may be a difficulty. There is minimal data on its clearance during continuous renal replacement therapy. Milrinone is most commonly administered intravenously but there are interesting reports of substantial benefits using the inhalational route. This is presumed to be due to a direct delivery to the pulmonary circulation with avoidance of systemic effects such as hypotension. A number of studies confirm the reduction in pulmonary arterial pressure and pulmonary artery resistance with maintenance of systemic pressure, especially in combination with vasopressors (Jeon et al., 2006). An additional benefit is an improvement of $\mathrm{PaO} 2 / \mathrm{FiO} 2$ ratio, due to optimization of ventilation/perfusion by the selective action on Milrinone delivery to only aerated alveoli. This improvement in oxygenation may further assist the right ventricle and decrease pulmonary arterial pressure by attenuating hypoxic pulmonary vasoconstriction (Wang et al., 2009).

\subsubsection{Pulmonary vasodilatation}

Increased pulmonary vascular resistance is often associated with, and worsens right ventricular dysfunction. Therefore another strategy for improving right ventricular function is to reduce pulmonary vascular resistance, thereby decreasing RV afterload. Nitric oxide (NO) can be easily administered and measured, and reduces pulmonary vascular resistance. It is commonly used after mitral valve and congenital heart surgery where right ventricular failure is a common occurence. Contrary to the evidence in ARDS where NO has no beneficial affect on clinical outcome, it is clear that NO reduces pulmonary vascular resistance in patients with idiopathic pulmonary arterial hypertension, and has a proven role in this situation. Prostacyclin may be nebulised or given intravenously. It is derived from pulmonary endothelial cells, and is used in the stable chronic pulmonary hypertensive 
patients in an intravenous form with good effect (Benedict et al., 2007). However in the critically ill population, significant systemic vasodilation limits the usefulness of intravenously administered Prostacyclin. Moreover, its effect on platelet aggregation precludes its use in patients at risk of bleeding. Nebulised Prostacyclin however avoids these risks and has a very short half-life. It may be given up to three hourly, and can be useful for extubating patients requiring $\mathrm{NO}$, who frequently become unstable when removing the last 1-2 parts per million. Nebulised drugs such as NO, Prostacyclin and Milrinone will not only reduce pulmonary vascular resistance but also optimize the ventilation-perfusion ratio since the drug is only delivered to aerated alveoli. Iloprost is an analogue of Prostacyclin with a much longer half-life of thirty minutes and a clinical activity of approximately sixty minutes. This makes it more practical to use in a critical care environment. These inhaled agents may be combined for improve synergistic affect. Research has been conducted investigating synergisitic combinations of Sildenafil and NO, Iloprost and NO, nebulised Milrinone and Prostacyclin, and Iloprost and Sildenafil, as well as the use of Sildenafil to allow safe weaning from NO (Huang J et al., 2011; Kumar et al., 2010; Lakshminrusimha et al., 2009; Lee et al., 2008; Winterhalter et al., 2010).

Oral Sildenafil has been used for the treatment of pulmonary hypertension in the critically ill for some time, and more recently has become available as an intravenous form. This phosphodiesterase type 5 inhibitor substantially decreases the pulmonary vascular resistance although a smaller reduction in systemic pressure also occurs. There is limited experience with intravenous sildenafil but this preparation would potentially be beneficial in patients who have inadequate gastric absorption due to splanchnic venous hypertension, a condition seen very frequently seen in patients with right ventricular dysfunction (Abrams et al., 2000; Barst et al., 1996; Prasad et al., 2000; Zhao et al., 2001)

\begin{tabular}{|c|c|c|c|}
\hline Goal & Drug & Route & Mechanism \\
\hline \multirow{3}{*}{$\begin{array}{l}\text { Prevention of } \\
\mathrm{RV} \\
\text { ischaemia }\end{array}$} & Noradrenaline & i.v. & \multirow{3}{*}{$\begin{array}{l}\text { Increases systemic (=aortic root) } \\
\text { pressure } \Rightarrow \text { improves right coronary } \\
\text { arterial filling }\end{array}$} \\
\hline & Adrenaline & i.v. & \\
\hline & Vasopressin & i.v. & \\
\hline \multirow{4}{*}{$\begin{array}{l}\text { Improve RV } \\
\text { output }\end{array}$} & Dobutamine & i.v. & \multirow{4}{*}{$\begin{array}{l}\text { Increases RV contractility } \\
\text { Inodilation } \Rightarrow \text { reduces PVR } \Rightarrow \\
\text { decreases RV afterload }\end{array}$} \\
\hline & Adrenaline & i.v. & \\
\hline & Levosimendan & i.v. & \\
\hline & $\begin{array}{l}\text { PDE3 inhibitors eg. } \\
\text { Milrinone }\end{array}$ & $\begin{array}{l}\text { i.v., } \\
\text { inhaled }\end{array}$ & \\
\hline \multirow{6}{*}{$\begin{array}{l}\text { Pulmonary } \\
\text { vasodilation }\end{array}$} & Nitric Oxide & inhaled & \multirow{6}{*}{$\begin{array}{l}\text { Dilates pulmonary vascular bed } \Rightarrow \\
\text { reduces } \mathrm{PVR} \Rightarrow \text { decreases } \mathrm{RV} \\
\text { afterload } \\
\text { Improves V/Q matching }\end{array}$} \\
\hline & Prostacyclin & $\begin{array}{l}\text { i.v., } \\
\text { inhaled }\end{array}$ & \\
\hline & Iloprost & i.v. & \\
\hline & Milrinone & $\begin{array}{l}\text { i.v., } \\
\text { inhaled }\end{array}$ & \\
\hline & $\begin{array}{l}\text { PDE5 inhibitors } \\
\text { eg. Sildenafil }\end{array}$ & i.v., p.o. & \\
\hline & $\begin{array}{l}\text { ET-receptor } \\
\text { antagonists } \\
\text { eg. Bosentan }\end{array}$ & p.o. & \\
\hline
\end{tabular}

Table 3. Medical management of pulmonary hypertension 
Endothelin antagonists such as Bosentan have minimal role in the critical care patient population as they take between three and six months to cause any effect. If they have been administered chronically to a patient, they should not be ceased acutely in ICU as this may induce rebound pulmonary hypertensive crisis. Care must be taken specifically with liver dysfunction.

Finally, some inotropic agents such as Milrinone, Dobutamine, Adrenaline and Levosimendan may have dual actions of improving cardiac output as well as reducing pulmonary vascular resistance (Chew et al., 2008; Jeon et al., 2006; Kerbaul et al., 2006; Le Tulza et al., 1997; Pagnamenta et al., 2003; Price et al., 2010;). A clinically useful systematic review with GRADE recommendations for the management of pulmonary vascular and right ventricular dysfunction may be found in Price et al (2010).

Regardless of drug and mechanical assistance to the patient with the failing right ventricle, there must be close and effective observation to assess response to therapy. Similarly, whilst volume challenges have a role in right ventricular failure, these should be small, with repeated assessment of adequacy of response, due to the impaired Frank-Starling mechanism.

\section{Conclusion}

Pulmonary hypertension occurs commonly in the critically ill population. The aetiology of this disease is varied and it is often associated with right ventricular failure. The presence of the latter increases mortality therefore treatment strategies for pulmonary hypertension also involve improving right ventricular function. The mainstay of therapy is pharmacological, and is aimed at reducing pulmonary vascular resistance, improving ventilation-perfusion matching and improving RV function. Commonly used therapies in critical care such as fluid loading, mechanical ventilation and vasopressor therapy have a place but must be used judiciously since they may worsen pulmonary vascular resistance and right ventricular function. Monitoring is essential in this population and a combination of right heart catheterization and Echo Doppler methods may be used. This paper provides an up-to-date review on the pathophysiology, monitoring and clinical management of pulmonary hypertension in critically ill adults.

\section{Acknowledgements}

MC was supported by the Acta Foundation, Region Skåne County Council (ALF), Lund University and the Anna Lisa and Sven Erik Lundgren's Foundation. A $\AA$ has received research grants from the ALF-project at Sahlgrenska University Hospital. JF declares that he is Chief Medical Officer at Bivacor TM.

\section{References}

Abrams, D., Schulze-Neick, I., \& Magee AG. (2000). Sildenafil as a selective pulmonary vasodilator in childhood primary pulmonary hypertension. Heart, 84(2), pp.E4

Aduen, JF., Castello, R., Daniels, JT., Diaz, JA., Safford, RE., Heckman, MG., Crook, JE., \& Burger, CD. (2011). Accuracy and precision of three echocardiographic methods for estimating mean pulmonary artery pressure. Chest, 139(2), pp.347-52 
Anavekar, NS., Gerson, D., Skali, H., Kwong, RY., Yucerl, K., \& Solomon SD. (2007). Twodimensional assessment of right ventricular function:an echocardiographic -MRI correlative study. Echocardiography, 24, pp.452-6

Badesch, DB., Champion, HC., Sanchez, MA., Hoeper, MM., Loyd, JE., Manes, A., McGoon, M., Naeije, R., Olchewski, H., Oudiz, RJ., \& Torbicki A. (2009). Diagnosis and assessment of pulmonary arterial hypertension. J Am Coll Cardiol, 54(1 Suppl), pp.S55 - S66

Barbier, C., Loubières, Y., Schmit, C., Hayon, J., Ricome, JL., Jardin, F., \& Viellard Baron A. (2004). Respiratory changes in inferior vena cava diameter are helpful in predicting fluid responsiveness in ventilated septic patients. Intensive Care Med, 30, pp.1740-46

Barst, RJ., Rubin, LJ., Long, WA., McGoon, MD., Rich, S., Badesch, DB., Groves, BM., Tapson, VF., Bourge ,RC., Brundage, BH., \& et al. (1996). A comparison of continuous intravenous epoprostenol (prostacyclin) with conventional therapy for primary pulmonary hypertension. The Primary Pulmonary Hypertension Study Group. N Engl J Med, 334(5):296-302

Benedict, N., Seybert, A., \& Mathier, MA. (2007). Evidence-based pharmacologic management of pulmonary arterial hypertension. Clin Ther, 29(10), pp.2134-53

Berkenbosch, JW., Baribeau, J., \& Perreault T. (2000). Decreased synthesis and vasodilatation to nitric oxide in piglets with hypoxia-induced pulmonary hypertension. Am J Physiol Lung Cell. Mol Physiol, 278, pp.L276-L283

Bove, AA. \& Santamore, WP. (1981). Ventricular interdependence. Prog Cardiovasc Dis, 23, pp.365-88

Brennan, JM., Blair, JE., Goonewardera, S., Ronan, A., Shah, D., Vasaiwala, S., Kirkpatrick, JN., \& Spencer KT. (2007). Reappraisal of the use of IVC for estimating RAP. J Am Soc Echocardiography, 20, pp.857-61

Burstin L. (1967). Determination of pressure in the pulmonary artery by external graphic recordings. Br Heart J, 29, pp.396-404

Chemla, D., Castelain, V., Provencher, S., Humbert, M., Simonneau, G., \& Hervé, P. (2009). Evaluation of various empirical formulas for estimating mean pulmonary artery pressure by using systolic pulmonary artery pressure in adults. Chest, 135(3), pp.760-8

Chew, MS., Bergenzaun, L., Öhlin, H., \& Ersson A. (2008). Pulmonary hypertension in the critically ill. Current Hypertension Reviews, 4, pp.150-60

Cournand, A., Motley, HL., Werkö, L., \& Richards DW Jr. (1948). Physiological studies of the effects of intermittent positive pressure breathing on cardiac output in man. Am J Physiol,152, pp.162-74

Damiano, RJ. Jr., La Follette, P. Jr., Cox, JL., Lowe, JE., \& Santamore WP. (1991). Significant left ventricular contribution to right ventricular systolic function. Am J Physiol, 261, pp.1514-24

Evora, PR., Pearson, PJ., \& Schaff, HV. (1993). Arginine vasopressin induces endotheliumdependent vasodilatation of the pulmonary artery. V1-receptor-mediated production of nitric oxide. Chest, 103(4), pp.1241-5

Farber, HW. \& Loscalzo, J. (2004). Pulmonary arterial hypertension. New Engl J Med, 351, pp. 1655-65

Feissel, M., Michard, F., Faller, JP., \& Teboul, JL. (2004). The respiratory variation in inferior vena cava diameter as a guide to fluid therapy. Intensive Care Med, 30, pp.1834-37

Fisher, MR., Forfia, PR., Chamera, E., Housten-Harris, T., Champion, HC., Girgis, RE., Corretti, MC., \& Hassoun, PM. (2009). Accuracy of Doppler echocardiography in 
the hemodynamic assessment of pulmonary hypertension. Am J Resp Crit Care Med, 179, pp.615-21

Forfia, PR., Fisher, MR., Mathai, SC., Housten-Harris, T., Hemnes, AR., Borlaug, BA., Chamera, E., Corretti, MC., Champion, HC., Abraham, TP., Girgis, RE., \& Hassoun PM. (2006). Tricuspid annular displacement predicts survival in pulmonary hypertension. Am J Resp Crit Care Med, 174(9), pp.1034-41

Fougères, E., Teboul, JL., Richard, C., Osman, D., Chemla, D., \& Monnet, X. (2010). Hemodynamic impact of a positive end-expiratory pressure setting in acute respiratory distress syndrome: importance of the volume status. Crit Care Med, 38, pp.802-7

Galie, N., Ussia, G., Passarelli, P., Parlangeli, R., Branzi, A., \& Mangani, B. (1995). Role of Pharmacologic tests in the treatment of primary pulmonary hypertension. Am J Cardiol, 75, pp.55A-62A

Ghighone, M., Girling, L., \& Prewitt, RM. (1984). Volume expansion versus norepinephrine in treatment of low cardiac output complicating an acute increase in right ventricular after load in dogs. Anesthesiology, 60(2), 132-5

Giaid, A., Yanagisawa, M., Langleben, D., Michel, RP., Levy, R., Shennib, H., Kimura, S., Masaki, T., Duguid, WP., \& Stewart, DJ. (1993). Expression of endothelin-1 in the lungs of patients with pulmonary hypertension. N Engl J Med, 328, pp.1732-9

Giaid, A. \& Saleh, D. Reduced expression of endothelial nitric oxide synthase in the lungs of patients with pulmonary hypertension. (1995). New Engl J Med, 333, pp.214-21

Gregory, SD., Timms, D., Gaddum, N., Mason, DG., \& Fraser, JF. (2011). Biventricular Assist Devices: A Technical Review. Ann Biomed Eng. Jul 8. [Epub ahead of print]

Hatle, L., Angelsen, BAJ., \& Tromsdal, A. (1981). Non-invasive estimation of pulmonary artery systolic pressure with Doppler ultrasound. Br Heart J, 45, pp.157-65

Hirsch, LJ., Rooney, MW., Wat, SS., Kleinmann, B., \& Mathru, M. (1991). Norepinephrine and Phenelephrine affects on right ventricular function in experimental canine pulmonary embolism. Chest, 100(3), pp.796-801

Höhn, L., Schweizer, A., Morel, DR., Spiliopoulos, A., \& Licker, M. (1999). Circulatory failure after anesthesia induction in a patient with severe primary pulmonary hypertension. Anesthesiology, 91, pp.1943-5

Huang, J., Bouvette, MJ., \& Zhou, J. (2010). Simultaneous delivery of inhaled prostacyclin and milrinone through a double nebulizer system. J Cardiothorac Vasc Anesth, 25(3), pp.590-1

Jacobs, AK., Leopold, JA., Bates, E., Mendes, LA., Sleeper, LA., White, H., Davidoff, R., Boland, J., Modur, S., Forman, R., \& Hochman, JS. (2003). Cardiogenic shock caused by right ventricular infarction: a report from the SHOCK registry. J Am Coll Cardiol, 241(8), pp.1273-9

Janda, S., Shahidi, N., Gin, K., \& Swiston, J. (2011). Diagnostic accuracy of echocardiography for pulmonary hypertension: a systematic review and meta-analysis. Heart, 97, pp.612-22

Jardin, F., Genevray, B., Brun-Ney, D., \& Bourdarias, JP. (1985). Influence of lung and chest wall compliance on transmission of airway pressure to the pleural space in critically ill patients. Chest, 88, pp.653-8

Jeon, Y., Ryum JH., Lim, YJ., Kim, CS., Bahk, JH., Yoon, SZ., \& Choi, JY. (2006). Comparative hemodynamic effects of vasopressin and norepinephrine after milrinone-induced hypotension in off-pump coronary artery bypass surgical patients. Eur J Cardiothorac Surg, 29(6), pp.952-6. 
Karnati, PK., El-Hajjar, M., Torosoff, M., \& Fein, SA. (2008). Myocardial performance index correlates with right ventricular ejection fraction measured by nuclear ventriculography. Echocardiography, 25, pp.381-5

Kumar, VH., Swartz, DD., Rashid, N., Lakshminrusimha, S., Ma, C., Ryan, RM., \& Morin, FC. 3rd. (2010). Prostacyclin and milrinone by aerosolization improve pulmonary hemodynamics in newborn lambs with experimental pulmonary hypertension. $J$ Appl Physiol,109(3), pp.677-84

Kerbaul, F., Rondelet, B., Demester, JP., Fesler, P., Huez, S., Naeije, R., \& Brimioulle, S. Effects of levosimendan versus dobutamine on pressure load-induced right ventricular failure. Crit Care Med, 34(11), pp.2814-9.

Lakshminrusimha, S., Porta, NF., Farrow, KN., Chen, B., Gugino, SF., Kumar, VH., Russell, JA., \& Steinhorn, RH. (2009). Milrinone enhances relaxation to prostacyclin and iloprost in pulmonary arteries isolated from lambs with persistent pulmonary hypertension of the newborn. Pediatr Crit Care Med,10(1), pp.106-12

Lang, RM., Bierig, M., Devereux, RB., Flachskampf, FA., Foster, E., Pellikka, PA., Pikard, MH., Roman, MJ., Seward, J., Shanewise, JS., Solomon, SD., Spencer, KT., Sutton, MS., \& Stewart, MJ. Chamber Quantification Writing Group; American Society of Echocardiography's Guidelines and Standards Committee; European Association of Echocardiography . (2005). Recommendations for Chamber Quantification: a report from the American Society of Echocardiography's Guidelines and Standards Committee and the Chamber Quantification Writing Group, developed in conjunction with the European Association of Echocardiography, a branch of the European Society of Cardiology. J Am Soc Echo, 18, 1440-63

Lee, JE., Hillier, SC., \& Knoderer, CA. (2008). Use of sildenafil to facilitate weaning from inhaled nitric oxide in children with pulmonary hypertension following surgery for congenital heart disease. J Intensive Care Med, 23(5), pp.329-34

Le Tulzo, Y., Seguin, P., Gacouin, A., Camus, C., Suprin, E., Jouannic, I., \& Thomas, R. (1997). Effects of epinephrine on right ventricular function in patients with severe septic shock and right ventricular failure: a preliminary descriptive study. Intensive Care Med, 23(6), pp.664-70.

Lindqvist, P., Waldenstrom, A., Henein, M., Morner, S., \& Kazzam, E. (2005). Regional and global right ventricular function in healthy individuals aged 20-90 years: a pulsed Doppler tissue imaging study:Umea General Population Heart Study. Echocardiography, 22, pp.305-14

Mandegar, M., Fung, Y-C B., Huang, W., Remillard, CV., Rubin, LJ., \& Yuan, J X-J. (2004). Cellular and molecular mechanisms of pulmonary vascular remodeling: role in the development of pulmonary hypertension. Microvasc Res, 68, pp.75-103

McGoon, M,. Gutterman, D., Steen, V., Barst, R., McCrory, DC., Fortinm TA., \& Loyd, JE; American College of Chest Physicians. (2004). Screening, early detection, and diagnosis of pulmonary arterial hypertension: ACCP evidence-based clinical practice guidelines. Chest, 126(1 Suppl), pp.14S- 34 S

McIntyre, KM. \& Sasahara, AA. (1971). The hemodynamic response to pulmonary embolism in patients without prior cardiopulmonary disease. Am J Cardiol, 28, pp.288-93

McLean, AS., Needham, A., Stewart, D., \& Parkin, R. (1997). Estimation of Cardiac Output in a critically ill subject by noninvasive echocardiographic techniques. Anaesthetics and Intensive Care 25(3), pp.250-4 
McLean ,AS., Ting, I., Huang, SJ., \& Wesley, S. (2007). The use of the right ventricular diameter and tricuspid annular tissue Doppler velocity parameter to predict the presence of pulmonary hypertension. Eur J Echo, 8, pp.128-36

Michard, F. \& Teboul, JL. (2000). Using heart-lung interactions to assess fluid responsiveness during mechanical ventilation. Crit Care, 4, pp.282-9

Moloney, ED. \& Evans, TW. (2003). Pathophysiology and pharmacological treatment of pulmonary hypertension in acute respiratory distress syndrome. Eur Resp J, 21, pp.720-7

Newman, JH., Wheeler, L., Lane, KB., Loyd, E., Gaddipati, R., Phillips, JA. 3rd., \& Loyd, JE. (2001). Mutation in the gene for bone morphogenetic protein receptor II as a cause of primary pulmonary hypertension in a large kindred. N Engl J Med,345,pp-319-24

Osman, D., Monnet, X., Castelain, V., Anguel, N., Warszawski, J., Teboul, JL., \& Richard, C. (2008). Incidence and prognostic value of right ventricular failure in acute respiratory distress syndrome. Int Care Med, 34, pp.873-80

Pagnamenta, A., Fesler, P., Vandinivit, A., Brimioulle, S., \& Naeije, R. (2003). Pulmonary vascular effects of dobutamine in experimental pulmonary hypertension. Crit Care Med, 31(4):1140-6

Prasad, S., Wilkinson, J., \& Gatzoulis, MA. Sildenafil in primary pulmonary hypertension. (2000). N Engl J Med, 2000;343(18), p.1342

Price, LC., Wort, SJ., Marino, PS., \& Brett, SJ. (2010). Pulmonary vascular and right ventricular dysfunction in critical care: current and emerging options for management: a systematic literature review. Crit Care, 14, pp.R169

Räsänen, J., Väisänen, IT., Heikkilä, J., \& Nikki, P. (1985). Acute myocardial infarction complicated by left ventricular dysfunction and respiratory failure: the effects of continuous positive airway pressure. Chest, 87, pp.158-62

Ribeiro, A., Lindmarker, P., Juhlin-Dannfelt, A., Johnsson, H., \& Jorfeldt, L. (1997). Echocardiography Doppler in pulmonary embolism: right ventricular dysfunction as a predictor of mortality rate. Am Heart J, 134, pp.479-87

Rudski, LG., Lai, WW., Afilalo, J., Hua, L., Handschumacher, MD., Chandreasekaran, K., Solomon, SD., Louie, EK., \& Schiller, NB. (2010). Guidelines for the Echocardiographic Assessment of the Right Heart in Adults: A Report from the American Society of Echocardiography endorsed by the European Association of Echocardiography, a registered branch of the European Society of Cardiology, and the Canadian Society of Echocardiography. J Am Soc Echo, 23, pp.685-713

Santamore, WP. \& Dell'Italia, LJ. (1998). Ventricular interdependence: Significant left ventricular contributions to right ventricular systolic function. Prog Cardiovasc Dis, 40, pp.289-308

Shekerdemian, L. \& Bohn, D. (1999). Cardiovascular effects of mechanical ventilation. Arch Dis Child, 80, pp.475-80

Steudel, W., Ichinose, F., Huang, PL., Hurford, WE., Jones, RC., Bevan, JA., Fishman, MC., \& Zapol, WM. (1997). Pulmonary vasoconstriction and hypertension in mice with targeted disruption of endothelial nitric oxide synthase (NOS3) gene. Circ Res, 81, pp.34-41

Strueber, M., Meyer, AL., Malehsa, D., \& Haverich, AE. (2010). Successful use of the HeartWare HVAD rotary blood pump for biventricular support. J Thorac Cardiovasc Surg 140(4), pp.936-7. 
Syyed, R., Reeves, JT., Welsh, D., Raeside, D., Johnson, MK., \& Peacock, AJ. (2008). The relationship between the components of pulmonary artery pressure remains constant under all conditions in both health and disease. Chest,133, pp.633-9

The Task Force for the Diagnosis and Treatment of Pulmonary Hypertension of the European Society of Cardiology (ESC) and the European Respiratory Society (ERS), endorsed by the International Society of Heart and Lung Transplantation (ISHLT). (2009). Guidelines for the diagnosis and treatment of pulmonary hypertension. Eur Heart J, 30, pp.2493-537

Timms, D., Fraser, J., Hayne, M., Dunning, J., McNeil, K., \& Pearcy, M. (2008). The BiVACOR rotary biventricular assist device: concept and in vitro investigation. Artif Organs, 32(10), pp.816-9

Timms, D., Gude, E., Gaddum, N., Lim, E., Greatrex, N., Wong, K., Steinseifer, U., Lovell, N., Fraser, J., \& Fiane, A. 2011. Assessment of Right Pump Outflow Banding and Speed Changes on Pulmonary Hemodynamics During Biventricular Support With Two Rotary Left Ventricular Assist Devices. Artif Organs, Jul 5. doi: 10.1111/j.15251594.2011.01283.x. [Epub ahead of print]

Trempy, GA., Nyhan, DP., \& Murray, PA. (1994). Pulmonary vasoregulation by arginine vasopressin in conscious, dhalothane-anesthetized, and pentobarbital-anesthetized dogs with increased vasomotor tone. Anesthesiology 81(3), pp.632-40.

Versprille, A. (1984). Pulmonary vascular resistance. A meaningless variable. Intensive Care Med,10, pp.51-3

Viellard Baron, A., Schmitt, J., Augarde, R., Fellahi, JL., Prin, S., Page, B., Beauchet, A., \& Jardin, F. (2001). Acute cor pulmonale in acute respiratory distress syndrome submitted to protective ventilation: Incidence, clinical implications and prognosis. Crit Care Med, 29(8), pp.1551-5

Wang, H., Gong, M., Zhou, B., \& Dai, A. (2009). Comparison of inhaled and intravenous Milrinone in patients with pulmonary hypertension undergoing mitral valve surgery. Adv Ther, 26(4), pp.462-468.

Weber, KT., Janicki, JS., Shroff, S., \& Fishman, AP. (1981). Contractile mechanisms and interaction of the right and left ventricles. American Journal of Cardiology, 47, pp.68695

Whittenberger, JL., McGregor, M., Berglund, E., \& Borst, HG. (1960). Influence of state of inflation of the lung on pulmonary vascular resistance. J Appl Physiol,15, pp.878-82.

Winterhalter, M., Antoniou, T., \& Loukanov, T. (2010). Management of adult patients with perioperative pulmonary hypertension: technical aspects and therapeutic options. Cardiology, 116(1), pp.3-9

Zhao, L., Mason, NA., Morrell, NW., Kojonazarov, B., Sadykov, A., Maripov, A, Mirrakhimov, MM., Aldashev, A., \& Wilkins, MR. (2001). Sildenafil inhibits hypoxia-induced pulmonary hypertension. Circulation, 104(4), pp.424-8

Zhao, L., Mason, NA., Strange, JW., Walker, H., \& Wilkins, MR. (2003). Beneficial effects of phosphodiesterase 5 inhibition in pulmonary hypertension are influenced by natriuretic peptide activity. Circulation,107:234-7 


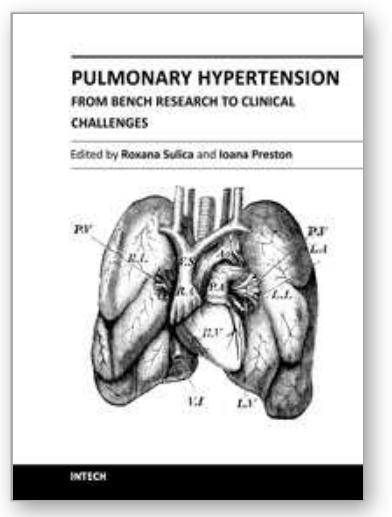

\section{Pulmonary Hypertension - From Bench Research to Clinical Challenges}

Edited by Dr. Roxana Sulica

ISBN 978-953-307-835-9

Hard cover, 326 pages

Publisher InTech

Published online 09, December, 2011

Published in print edition December, 2011

The textbook "Pulmonary Hypertension - From Bench Research to Clinical Challenges" addresses the following topics: structure and function of the normal pulmonary vasculature; disregulated cellular pathways seen in experimental and human pulmonary hypertension; clinical aspects of pulmonary hypertension in general; presentation of several specific forms of pulmonary hypertension, and management of pulmonary hypertension in special circumstances. The textbook is unique in that it combines pulmonary and cardiac physiology and pathophysiology with clinical aspects of the disease. First two sections are reserved for the basic knowledge and the recent discoveries related to structure and cellular function of the pulmonary vasculature. The chapters also describe disregulated pathways known to be affected in pulmonary hypertension. A special section deals with the effects of hypoxia on the pulmonary vasculature and the myocardium. Other three sections introduce the methods of evaluating pulmonary hypertension to the reader. The chapters present several forms of pulmonary hypertension which are particularly challenging in clinical practice (such as pulmonary arterial hypertension associated with systemic sclerosis), and lastly, they address special considerations regarding management of pulmonary hypertension in certain clinical scenarios such as pulmonary hypertension in the critically ill.

\section{How to reference}

In order to correctly reference this scholarly work, feel free to copy and paste the following:

Michelle S. Chew, Anders Åneman, John F. Fraser and Anthony S. McLean (2011). Pulmonary Hypertension in the Critically III, Pulmonary Hypertension - From Bench Research to Clinical Challenges, Dr. Roxana Sulica (Ed.), ISBN: 978-953-307-835-9, InTech, Available from: http://www.intechopen.com/books/pulmonaryhypertension-from-bench-research-to-clinical-challenges/pulmonary-hypertension-in-the-critically-ill

\section{INTECH}

open science | open minds

\author{
InTech Europe \\ University Campus STeP Ri \\ Slavka Krautzeka 83/A \\ 51000 Rijeka, Croatia \\ Phone: +385 (51) 770447 \\ Fax: +385 (51) 686166 \\ www.intechopen.com
}

\author{
InTech China \\ Unit 405, Office Block, Hotel Equatorial Shanghai \\ No.65, Yan An Road (West), Shanghai, 200040, China \\ 中国上海市延安西路65号上海国际贵都大饭店办公楼 405 单元 \\ Phone: +86-21-62489820 \\ Fax: +86-21-62489821
}


(C) 2011 The Author(s). Licensee IntechOpen. This is an open access article distributed under the terms of the Creative Commons Attribution 3.0 License, which permits unrestricted use, distribution, and reproduction in any medium, provided the original work is properly cited. 